\title{
Study on Effect of Superplasticizer on GGBS Blended
}

\section{Geopolymer Concrete}

\author{
Vahini M..$^{{ }^{*}}$, K. Manjunatha ${ }^{2}$, Venkatesh ${ }^{3} \&$ Basappa Meti $^{{ }^{* *}}$, \\ ${ }^{1}$ Department of Civil Engineering, Government Engineering College, Haveri, India \\ ${ }^{2}$ VTU Regional Office, Mysore, India \\ ${ }^{3}$ Government Engineering College, Kushalnagara, India \\ *Vahini M., E-mail: vahini_cta@yahoo.com; \\ ** Basappa Meti, E-mail: bsmeti@gmail.com
}

Received: June 21, 2019 Accepted: July 9, 2019 Online Published: September 3, 2019

doi:10.22158/ees.v2n2p45 URL: http://dx.doi.org/10.22158/ees.v2n2p45

\begin{abstract}
Geopolymer concrete is an alternate to conventional concrete with reduced carbon emission, embodied energy and global warming potential and transforming waste product into an useful material. Geopolymer concrete is produced by mixing highly alkaline activator solution with alumino silicate source materials. Geopolymer concrete is highly viscous or sticky in nature, to overcome this drawback, an attempt has been made to study the effect of naphthalene based superplasticizer on geopolymer concrete blended with GGBS. Fly ash was replaced by GGBS at 20\% increment levels, keeping a constant superplasticizer dosage at $3 \%$ by weight of binding material. Workability and strength characteristics were compared with those of geopolymer concrete blended with GGBS without superplasticizer. Up to certain replacement level of fly ash with GGBS, results in decrease of strength parameters with increase in workability, further replacement results in increase of strength with reduced workability with the addition of superplasticizer.
\end{abstract}

\section{Keywords}

ground granulated blast furnace slag(GGBS), fly ash, superplasticizer, blended geopolymer concrete

\section{Introduction}

\subsection{General}

Concrete is the widely used material in the world after water. Ordinary Portland cement has been used traditionally as a binding material for preparation of concrete. The world-wide consumption of concrete is believed to rise exponentially for the infrastructural development taking place in China and India. One tone of carbon dioxide is estimated to be released to the atmosphere when one ton of ordinary Portland cement is manufactured; also the emission by cement manufacturing process contributes $7 \%$ 
to the global carbon dioxide emission. It is important to find an alternate binder which has less carbon footprint than cement. Geopolymer concrete is one such alternate binding material, wherein the cement is totally replaced by industrial byproducts such as fly ash, GGBS etc., with rich content of aluminium and silicon. Davidovits $(1988 ; 1994)$ proposed that an alkaline liquid could be used to react with the Silicon (Si) and Aluminum (Al) in a source material of geological origin or in by product materials such as fly ash and GGBS to produce binders. Because the chemical reaction that takes place in this case is a polymerization process, he coined the term geopolymer to represent these binders. The final properties of geopolymer concrete is influenced by large number of factors like type of curing, water content, alkali concentration, solids content, silicate and aluminates ratio, $\mathrm{pH}$ and others.

Geopolymer concrete is highly viscous or sticky in nature, which reduces the workability. To increase the workability, extra water or superplasticizer will be added. Therefore, the present work aims to study the effect of adding superplasticizer on workability and strength characteristics of GGBS blended geopolymer concrete.

\subsection{Constituents of Geopolymer Concrete}

Geopolymer concrete can be manufactured by using the low-calcium fly ash obtained from coal-burning power stations. Most of the fly ash available globally is low-calcium fly ash formed as a by-product of burning anthracite or bituminous coal. Although coal burning power plants are considered to be environmentally unfriendly, the extent of power generated by these plants is increasing due to the huge reserves of good quality coal available worldwide and the low cost of power produced from these sources. The energy returned-to-energy invested ratio of coal burning power plants is high, and second only to the hydro-power generation plants. (Lloyd, 2009)

The main constituents of the geopolymer concrete are source materials and alkaline liquids. The source materials should be rich in silicon (si) and aluminum (Al), these could be natural materials such as kaolin, clays etc. Alternatively, by-product materials such as fly ash, silica fume, slag, rice husk ash, red mud etc. could be used as source materials. The choice of the source materials for making geopolymers depends on factors such as availability, cost, type of application, specific demand of the end users. The alkaline liquids are from soluble alkali metals that are usually sodium or potassium based.

\section{Literature Review}

Nuruddin et al. (2011) have studied the effect of superplasticizer (SP) dosage and molarity of $\mathrm{NaOH}$ solution on workability and compressive strength of Self-Compacting Geopolymer Concrete. The workability properties such as filling ability, passing ability and resistance to segregation were assessed using slump flow, T-50, V-funnel, L-Box and J-ring test methods. It was found that the essential workability requirements for self compactability were satisfied. Results show that low superplasticizer content 3, 4 and 5\% had poor filling and passing ability and the workability results were not satisfied the limits of self compacting concrete. As the concentration of $\mathrm{NaOH}$ solution increased from $8 \mathrm{M}$ to $12 \mathrm{M}$, the compressive strength of geopolymer concrete has increased. They have concluded that $6 \%$ of 
SP dosage and $12 \mathrm{M}$ of $\mathrm{NaOH}$ concentration as the optimum values.

Laskar and Bhattacharjee (2012) have made an attempt to study variation of workability of fly ash based geopolymer concrete with the variation of lignin based plasticizer and polycarboxylic ether based superplasticizer. It has been observed that there exists a critical value of molar strength of sodium hydroxide beyond which superplasticizer and plasticizer have adverse effect on workability of fly ash based geopolymer concrete. Below the critical molar strength of sodium hydroxide, there is an increase in slump. Plasticizer and superplasticizer dosage improves workability of fly ash based geopolymer concrete for molar strength of $\mathrm{NaOH}$ solution less than 4M. Lignin based superplasticizer has been found to be more effective than PC based superplasticizer.

Nematollahi and Sanjayan (2014) have presented a review on efficacy of available superplasticizers on geopolymers. The effect of SPs on workability, strength and rheological parameters (yield stress and plastic viscosity) of slag and fly ash based geopolymer paste, mortar and concrete was comprehensively reviewed in this study. In summary, research results reported in the literature ascertain that SPs do not work the same on geopolymer systems than in OPC systems. The effect of SPs on slag and fly ash based geopolymers directly depends on the type of binder and activators in addition to the type and dosage of the SPs as well as the $\mathrm{pH}$ of the alkaline solution. In general, the PC based SPs (latest generation) are the most effective type in the case of fly ash based geopolymer activated by $\mathrm{NaOH}+\mathrm{Na}_{2} \mathrm{SiO}_{3}$ activators. Whereas, in the case of slag based geopolymers activated by $\mathrm{NaOH}$ solution, $\mathrm{N}$ based SPs (second generation) are the most efficient type. Moreover, in most cases using SPs might decrease the strength of the slag and fly ash based geopolymers with reference to the original geopolymers without using SP.

Nematollahi and Sanjayan (2014) have evaluated the effect of different commercial superplasticizers (SPs) such as naphthalene, melamine and modified polycarboxylate based on the workability and strength of a class F fly ash geopolymer paste activated by two different activator combinations i.e., 8M sodium hydroxide solution and a multi-compound activator composed of 8M NaOH solution (28.6\%) + $\mathrm{Na}_{2} \mathrm{SiO}_{3}(71.4 \%)$ with a $\mathrm{SiO}_{2} / \mathrm{Na}_{2} \mathrm{O}$ ratio of 2.0 . These SPs at a dosage of $1 \%$ by mass of fly ash were added to the fresh paste and flowability of the activated fly ash paste measured via mini slump test and compared with that of paste without using any SP. The experimental results indicated that the effect of different SPs on the workability and strength of fly ash based geopolymer directly depends on the type of activator and the SP. In the case of using $8 \mathrm{M} \mathrm{NaOH}$ solution as the activator, naphthalene based SP was an effective type; whereas modified polycarboxylate based SP was the most efficient type when the multi-compound activator was used.

Xie and Kayali (2015) have investigated the use of superplasticizers with enhanced dispersion capability for different geopolymer pastes. Two types of polycarboxylate based and one type of naphthalene based superplasticizer were investigated. Results showed that all the applied superplasticizers were considerably less effective with geopolymers, a higher than usual dosage of superplasticizer was needed for noticeable workability enhancements. Naphthalene based Published by SCHOLINK INC. 
superplasticizers caused higher instantaneous slump and larger spread than polycarboxylate based type.

\section{Materials and Methodology}

\subsection{Materials}

The alumino silicate material used in this study is a combination of fly ash and ground granulated blast furnace slag (GGBS). Fly ash is procured from Bellary thermal power plant, Kudithini. GGBS is obtained from JSW, Bellary. Sodium silicate and Sodium hydroxide are procured from Shree Chem, Bangalore and locally available coarse and fine aggregates are used. Table 1 shows the physical properties of materials used. Sodium hydroxide used is in flakes form with $97 \%$ purity, concentration of sodium silicate solution is $47.50 \%$ with $\mathrm{Na}_{2} \mathrm{O} 14.7 \%$ and $\mathrm{SiO}_{2} 32.8 \%$. Conplast $\mathrm{SP} 430$ is used as Naphthalene based superplasticizer.

Table 1. Physical Properties of Materials Used

\begin{tabular}{ccccc}
\hline Material & Fly ash & GGBS & Fine aggregate & Coarse aggregate \\
\hline Specific Gravity & 2.20 & 2.79 & 2.42 & 2.5 \\
\hline
\end{tabular}

\subsection{Mix Proportions}

As there are no codal provisions for the mix design of geopolymer concrete, the geopolymer concrete mix was prepared as per the procedure given by Patankar et al. The alkaline liquid to fly ash ratio is kept as 0.35 . The ratio of sodium hydroxide to sodium silicate is taken as 1.00 Concentration of sodium hydroxide solution is maintained as 13M. Mix design is carried out for M30 grade of geopolymer concrete. Quantity of materials required is shown in Table 2.

Table 2. Quantity of Ingredients of M30 Geopolymer Concrete

\begin{tabular}{lccccccc}
\hline $\begin{array}{l}\text { Ingredient of } \\
\text { geopolymer } \\
\text { concrete }\end{array}$ & $\begin{array}{l}\text { Fly } \\
\text { ash }\end{array}$ & $\mathrm{NaOH}$ & $\mathrm{Na}_{2} \mathrm{SiO}_{3}$ & Sand & $\begin{array}{r}\text { Coarse } \\
\text { aggregate }\end{array}$ & $\begin{array}{r}\text { Total } \\
\text { water } \\
\text { Content }\end{array}$ & $\begin{array}{c}\text { Extra } \\
\text { Water }\end{array}$ \\
\hline Quantity $\left(\mathrm{kg} / \mathrm{m}^{3}\right)$ & 405 & 70.875 & 70.875 & 686.81 & 1261.56 & 110 & 31.48 \\
\hline
\end{tabular}

\subsection{Casting and Curing}

Fine aggregate, coarse aggregate, fly ash are mixed in dry condition for 3-4 minutes and then the alkaline solution, which is a combination of sodium hydroxide solution and sodium silicate solution with superplasticizer dosage of $3 \%$ by weight of binding material is added to the dry mix. Figure 1 shows the casting of specimens. Specimens are demoulded after 24 hrs of casting and kept in ambient condition for curing as shown in Figure 2. 


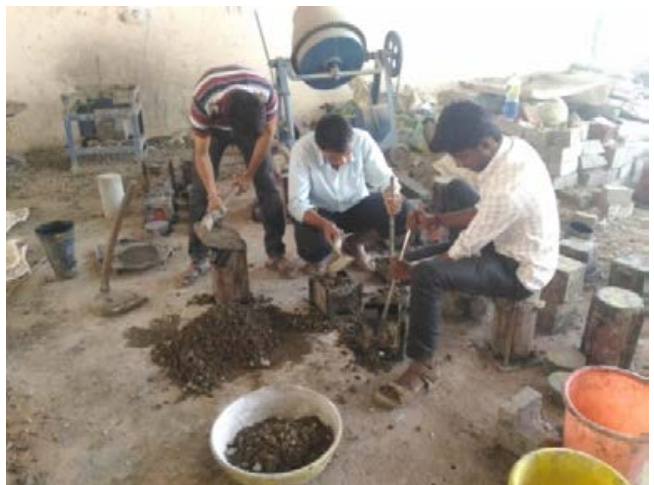

Figure 1. Casting of Specimens

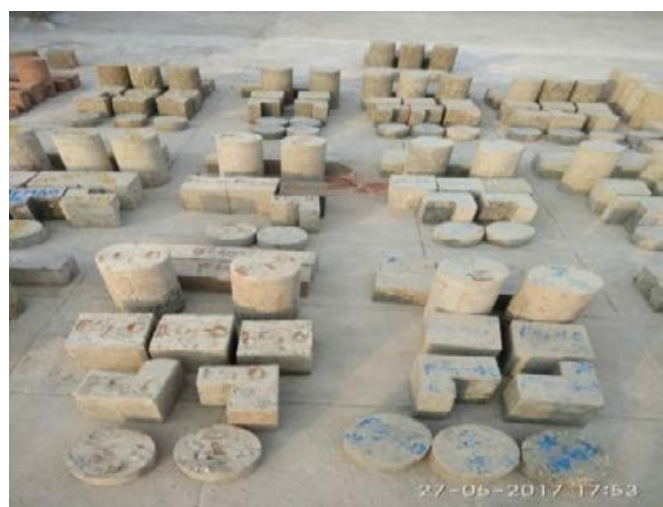

Figure 2. Specimens at Ambient Curing

\section{Results and Discussions}

The specimens are designated as FA100 for 100\% fly ash and FGn for fly ash and GGBS blends at n\% of fly ash. Fly ash is replaced at an increment of $20 \%$ by weight with GGBS. Workability and strength characteristics are studied for GGBS blended geopolymer concrete with and without SP.

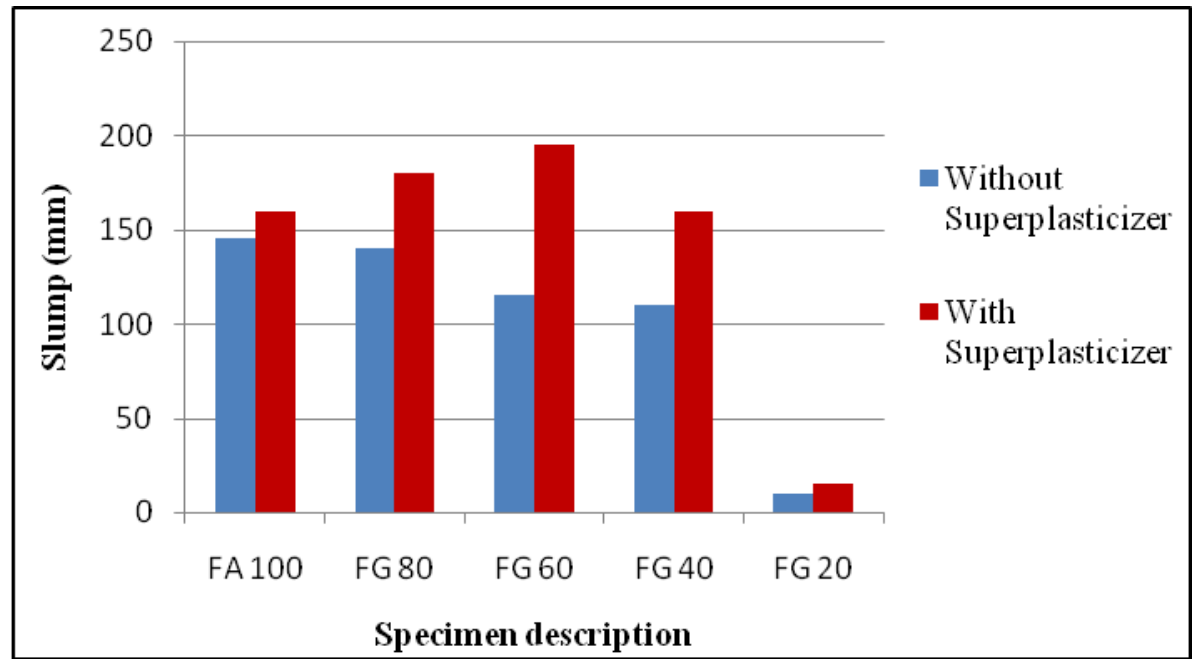

Figure 3. Slump for GGBS Blended Geopolymer Concrete with and without Superplasticizer

Workability in terms of slump is shown in Figure 3. It is observed that the slump for geopolymer concrete with superplasticizer is more when compared with geopolymer concrete without superplasticizer, for all replacements of fly ash with GGBS. Slump for geopolymer concrete without superplasticizer, reduces with increase in GGBS level but for geopolymer concrete with superplasticizer, slump increases up to $40 \%$ replacement of fly ash with GGBS and then it decreases which may be due to the presence of calcium in GGBS.

Strength properties such as compressive strength, split tensile strength and flexural strength are conducted for GGBS blended geopolymer concrete with and without superplasticizer and the results are shown in Table 3. 
Table 3. Strength Properties of Geopolymer Concrete Blended with GGBS with and without Superplasticizer

\begin{tabular}{ccccccc}
\hline & \multicolumn{2}{c}{$\begin{array}{c}\text { Compressive Strength } \\
\text { (MPa) }\end{array}$} & \multicolumn{2}{c}{$\begin{array}{c}\text { Split Tensile Strength } \\
(\mathrm{MPa})\end{array}$} & \multicolumn{2}{c}{ Flexural Strength (MPa) } \\
\cline { 2 - 7 } Specimen & Without & With & Without & With & Without & With \\
description & $\begin{array}{c}\text { Superplast } \\
\text { icizer }\end{array}$ & $\begin{array}{c}\text { Superplast } \\
\text { icizer }\end{array}$ & $\begin{array}{c}\text { Superplast } \\
\text { icizer }\end{array}$ & $\begin{array}{c}\text { Superplasti } \\
\text { cizer }\end{array}$ & $\begin{array}{c}\text { Superplasti } \\
\text { cizer }\end{array}$ & $\begin{array}{c}\text { Superplasti } \\
\text { cizer }\end{array}$ \\
\hline FA 100 & 45.04 & 42.67 & 5.19 & 4.01 & 7.60 & 7.53 \\
FG 80 & 50.37 & 48.89 & 5.19 & 4.95 & 8.40 & 7.73 \\
FG 60 & 60.37 & 54.22 & 5.38 & 5.00 & 9.40 & 8.00 \\
FG 40 & 47.33 & 60.44 & 3.21 & 5.19 & 5.40 & 8.67 \\
FG 20 & 21.56 & 55.70 & 2.50 & 4.95 & 1.33 & 7.47 \\
\hline
\end{tabular}

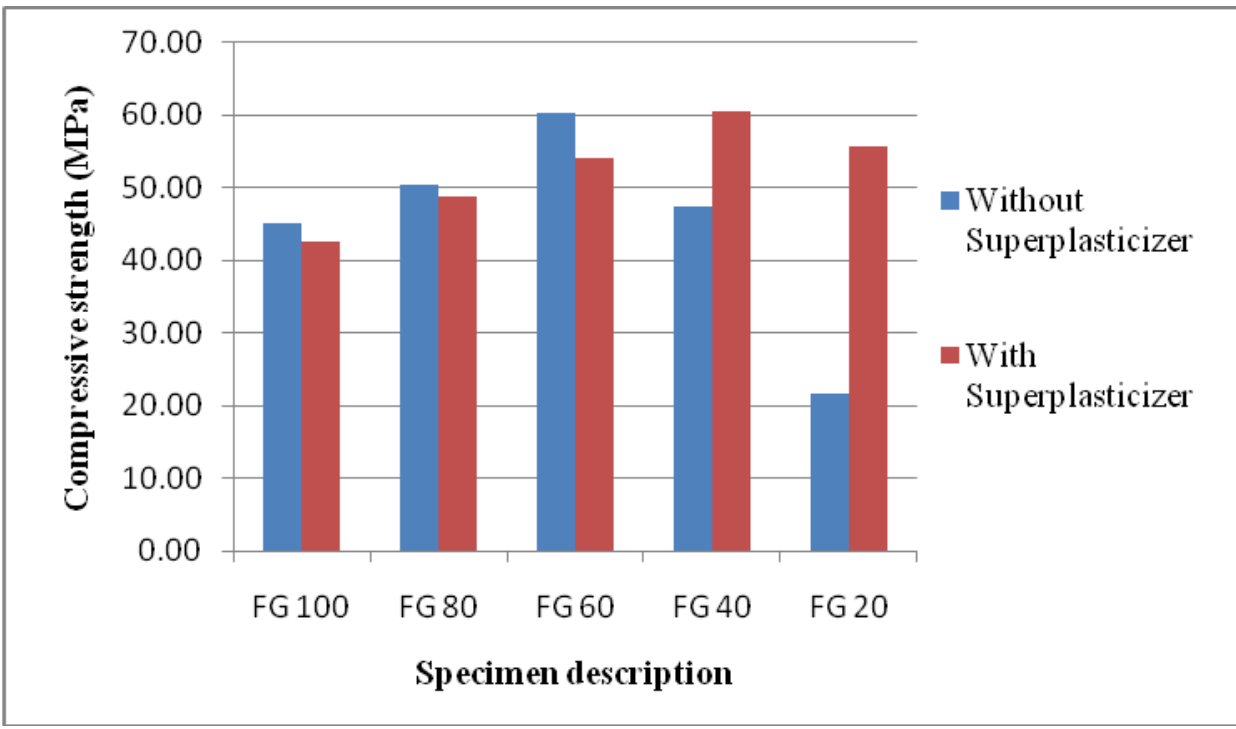

Figure 4. Compressive Strength for GGBS Blended Geopolymer Concrete with and without Superplasticizer 


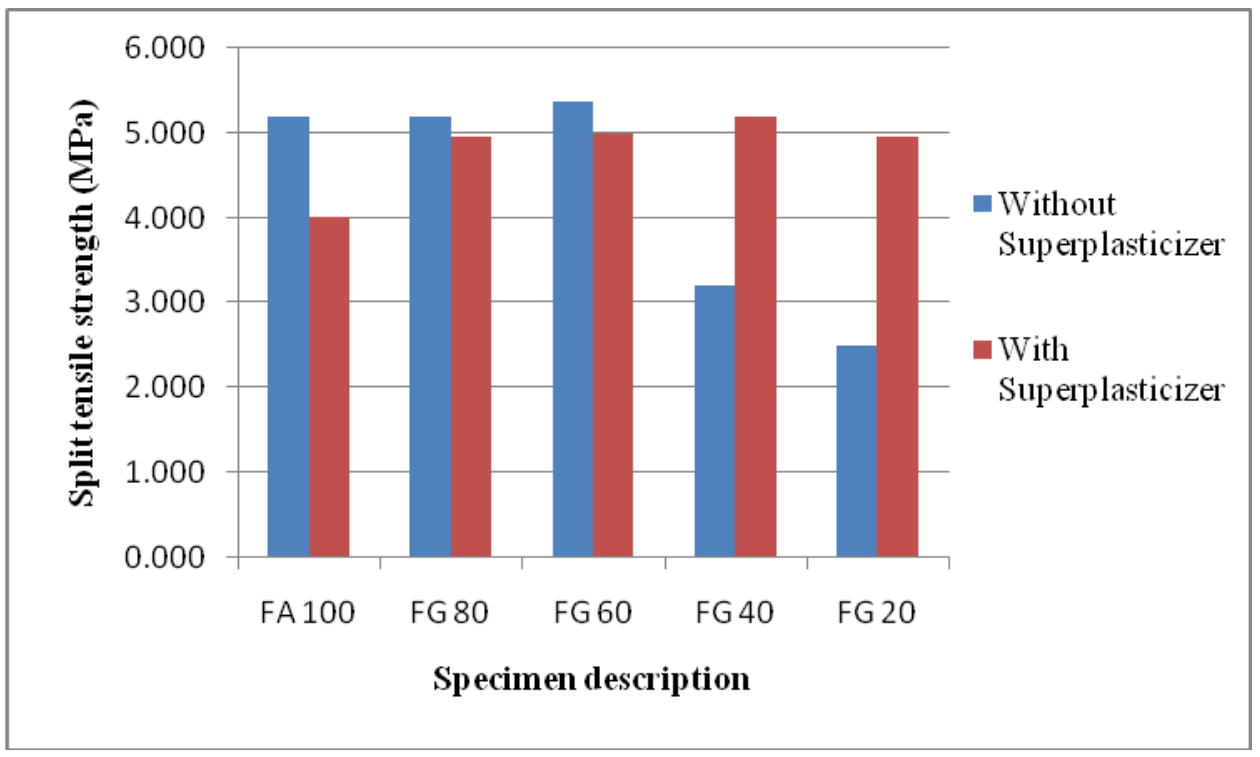

Figure 5. Split Tensile Strength for GGBS Blended Geopolymer Concrete with and without Superplasticizer

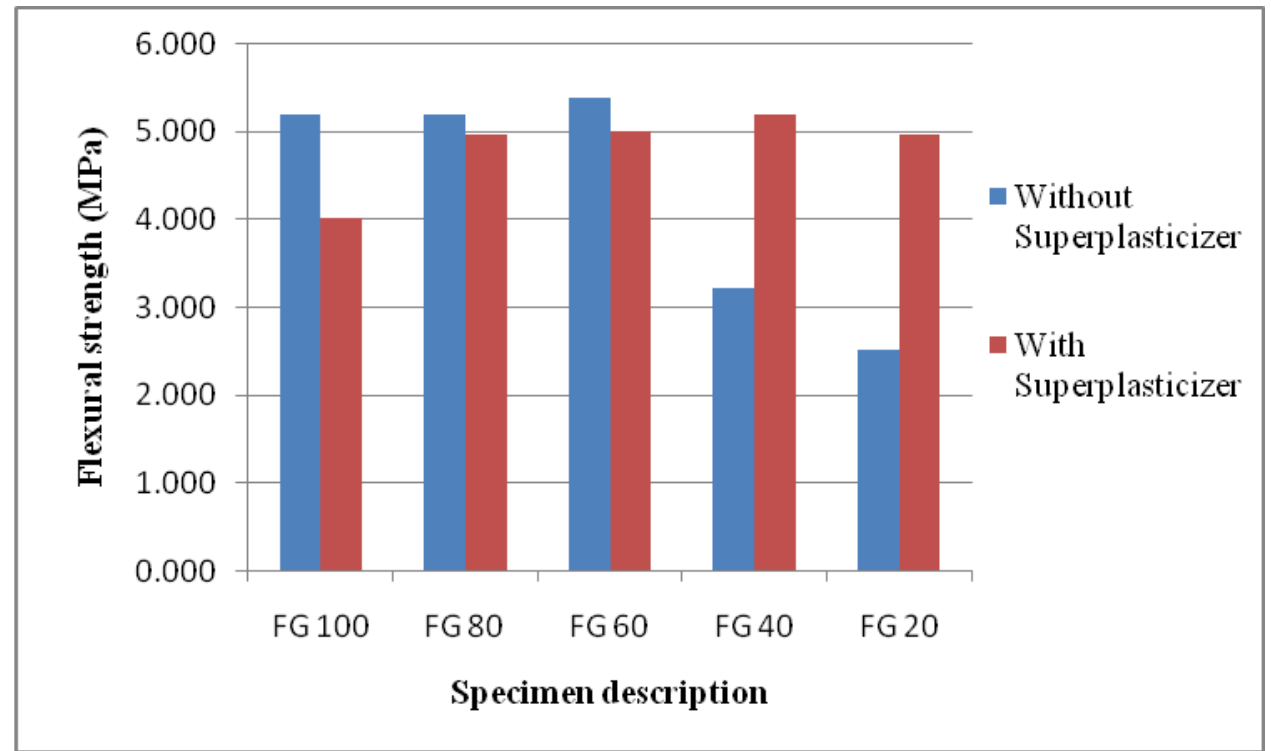

Figure 6. Flexural Strength for GGBS Blended Geopolymer Concrete with and without Superplasticizer

Compressive strength, split tensile strength and flexural strength for GGBS blended geopolymer concrete with and without superplasticizer are shown in Figure 4 to 6 respectively. Upto $40 \%$ replacement of fly ash with GGBS, all strength parameters such as compressive strength, split tensile strength and flexural strength reduce with the addition of superplasticizer, when compared to geopolymer concrete without superplasticizer, due to unstability of superplasticizer in highly alkaline activator condition. Beyond $40 \%$ replacement, all strength parameters increase with the addition of superplasticizer due to reduced activator to slag ratio, which agrees with the past research.

Published by SCHOLINK INC. 


\section{Conclusions}

In this study the effect of naphthalene based superplasticizer on GGBS blended geopolymer concrete has been made. Based on the experimental results, following conclusions are drawn.

- Workability increases with the addition of superplasticizer for all replacement levels of GGBS. Maximum of $40 \%$ increase in workability is observed for $40 \%$ replacement of fly ash with GGBS.

- Strength properties are decreased by $20 \%$ upto $40 \%$ replacement level when superplasticizer is added.

- Strength properties such as compressive strength reduces by $10 \%$, split tensile strength reduces by $20 \%$ and flexural strength reduces by $20 \%$, when fly ash is replaced upto $40 \%$ with GGBS with the addition of superplasticizer.

- Strength properties are increased by 100 to $450 \%$ with the addition of superplasticizer beyond $40 \%$ replacement level of fly ash with GGBS.

- $\quad$ FG60 i.e., $60 \%$ fly ash + 40\% GGBS is the optimum blend without superplasticizer and FG40 i.e., $40 \%$ fly ash $+60 \%$ GGBS is the optimum blend with superplasticizer.

\section{References}

Carabba, L., Manzi, S., \& Bignozzi, M. C. (2016). Superplasticizer Addition to Carbon Fly Ash Geopolymers Activated at Room Temperature. Materials, 9, 586. https://doi.org/10.3390/ma9070586

Fadhil, N. M., Demie, S., Fareed, A. M., \& Shafiq, N. (2011). Effect of Superplasticizer and NaOH Molarity on Workability, Compressive Strength and Microstructure Properties of Self-Compacting Geopolymer Concrete. International Journal of Civil and Environmental Engineering, 3(2), $122-129$.

Laskar, A. I., \& Bhattacharjee, R. (2012). Effect of Plasticizer and Superplasticizer on Workability of Fly Ash Based Geopolymer Concrete. Proceedings of International Conference on Advances in Architecture and Civil Engineering (AARCV 2012), 21st-23rd June 2012.

Lloyd, N., \& Rangan B. V. (2009). Geopolymer Concrete; Sustainable Cementless Concrete (pp. 33-54). Proceeding of the $10^{\text {th }}$ ACI International Conference on Recent Advances in Concrete Technology and Sustainability Issues, Seville, ACISP-261.

Nematollahi, B., \& Sanjayan, J. (2013). Effect of Superplasticizers on Workability of Fly Ash Based Geopolymer (pp. 713-719). In CIEC 2013, Proceedings of the International Civil and Infrastructure Engineering Conference. https://doi.org/10.1007/978-981-4585-02-6_61

Nematollahi, B., \& Sanjayan, J. (2014). Effect of different superplasticizers and activator combinations on workability and strength of fly ash based geopolymer concrete. Materials and Design, 57, 667-672. https://doi.org/10.1016/j.matdes.2014.01.064 
Nematollahi, B., \& Sanjayan, J. (2014). Efficacy of Available Superplasticizers on Geopolymers.

Research Journal of Applied Sciences, Engineering and Technology, 7(7), 1278-1282. https://doi.org/10.19026/rjaset.7.420

Patankar, S. V., Ghugal, Y. M., \& Jamkar, S. S. (2015). Mix Design of Fly Ash Based Geopolymer Concrete. In Advances in Structural Engineering (pp 1619-1634). Springer India. https://doi.org/10.1007/978-81-322-2187-6_123

Xie, J. T., \& Kayali, O. (2015). Effect of superplasticizer on workability enhancement of class $F$ fly ash- based geopolymers. 2015 world of coal ash(WOCA) conference in Naschille, TN- May 5-7. 